\title{
"Donde hace nido el avión": estéticas (in)augurales movidas por la historia de la aviación (o los futurismos entre Latinoamérica, Marinetti y Le Corbusier) ${ }^{1}$
}

\author{
"Where the plane makes its nest": (in)augural aesthetics shifted by the history of \\ aviation (futurisms between Latin America, Marinetti and Le Corbusier)
}

Rike Bolte

rbolte@uninorte.edu.co

Universidad del Norte Barranquilla, Colombia

Cita sugerida: Bolte, R. (2021). "Donde hace nido el avión": estéticas (in)augurales movidas por la historia de la aviación (o los futurismos entre Latinoamérica, Marinetti y Le Corbusier). Orbis Tertius, 26(33), e199. https://doi.org/10.24215/18517811e199
Resumen: El inicio de la aviación moderna conduce a una estética que, si bien se vio prefigurada en forma de mitos clásicos - una serie de experimentos tecnológicos y (proto-)humanistas durante la Edad Media, Moderna y Contemporánea temprana; y que más tarde sería recibida por las poéticas prevanguardistas del siglo XIX-, alza el vuelo con la euforia tecnológica a principios del siglo XX. Sin olvidar que esta euforia también accionó las Guerras Mundiales, el presente artículo ahonda en la historia cultural del vuelo, en cómo las primeras máquinas voladoras del siglo XX, con sus respectivas ideologías, sustentaron varios programas estéticos que plasmaron el "modo avión" y la experiencia perceptiva del piloto como un verdadero paradigma. El "modo avión" sería transcrito por el futurismo transcultural, y especialmente compartido por el mundo italiano, francés e hispanófono. Conforme el artículo traza esta historia, se perfila toda una cultura impregnada por el espíritu de la aviación, incluyendo las visiones utópicas del urbanismo y la arquitectura aeroportuaria. Sondeando en estos campos como en los terrenos literarios (los poéticos y los narrativos) el artículo, además, se explaya sobre el tópico del "cielo abierto".

Palabras clave: Marinetti, Huidobro, Maples Arce, Le Corbusier, Espacios aeroportuarios.

Abstract: The beginning of modern aviation leads to an aesthetic that, although foreshadowed in the form of classical myths as well as in a series of technological and (proto)humanist experiments during the Middle Ages, the early Modern Age and the subsequent centuries, "takes flight" with technological euphoria at the beginning of the 20th century. Without forgetting that this euphoria also triggered the World Wars, the present essay delves into this fascinating chapter of cultural aircraft history and outlines how the first flying machines of the 20th century and their respective ideologies supported various aesthetic programs that gave birth to the so-called 'flight mode'. In fact, the pilot's perceptive experience became a paradigm with great importance for transcultural futurism - and especially within the Italian, French and Spanish-speaking world. In this light, the essay examines a culture deeply moved by the spirit of aviation (including utopian ways of urbanism and 
airport architecture) and furthermore examines both poetic and narrative literary topics, such as the idea of the "open sky".

Keywords: Marinetti, Huidobro, Maples Arce, Le Corbusier, Airport Spaces.

\section{Y el avión trae un lenguaje diferente Para la boca de los cielos siempre \\ Vicente Huidobro}

The air is the only place free from prejudices

Bessie Coleman

\section{EL ESPÍRITU DE LA AVIACIÓN}

El entusiasmo por la aviación y la correspondiente poética, aunque haya germinado mucho antes de la modernidad estética, nace con las máquinas voladoras del temprano siglo XX y las ideologías contemporáneas. En este contexto, sin duda, resalta el credo beligerante del futurismo italiano; y el primer manifiesto de Filippo Tommaso Marinetti sella un momento augural, en el sentido más global, al cual se adhieren muchos otros autores (y también pioneros de la aviación). Como se evidenciará en las próximas páginas, el futurismo, empero, tiene muchas aristas: efectivamente toma la forma de un fenómeno transcultural cuya estructuración, altamente dinámica, se articula no solamente entre los países europeos sino además entre continentes. Atravesadas por las guerras y posguerras y otros escenarios de una muy dialéctica modernización, las sociedades europeas y americanas comparten y a la vez compiten por los espacios, especialmente por aquellos de adscripción utópica. En este trajín se diseñan máquinas, edificios, ambientes y textos.

En lo que sigue se hará un recuento de las respuestas programáticas y poéticas que conciernen al paradigma del vuelo y que fueron lanzadas desde el mundo italiano e hispanófono. Asimismo, se arrojará luz sobre una cultura impregnada por el espíritu de la aviación compartido entre Europa e Hispanoamérica, incluyendo algunos aspectos del futurismo urbanístico y de la estética aeroportuaria. A modo de cierre, el ensayo abordará el tópico del "cielo abierto", tanto en la literatura como en el sentido más amplio de las expresiones culturales.

\section{ENGENDROS METÁLICOS Y PROTOCOLOS POÉTICOS DE VUELO: LOS CAMPOS DE BATALLA DEL FUTURISMO}

Las vanguardias históricas fueron pronunciadas mediante los manifiestos de los distintos ismos, como fue el caso, por antonomasia, del futurismo. Es de sobra conocido el papel pionero del "Manifesto del Futurismo" de Marinetti, publicado en febrero de 1908 en el Giornale dell'Emilia y en el mismo mes en Le Figaro. Este manifiesto incluye el relato de su propia fundación y creación, y expone claves e imperativos futuristas. Sembrando cierta fama de paradójico (Hinz, 1985, p. 46; Van den Berg, 2014, p. 323), el futurismo abre un plano vehicular y lo ventila en su extremado afán por la aceleración, un gesto precipitante que se sigue dirigiendo hacia el cielo, por más que este haya perdido su otrora aura protectora. En esta idolatría de la energía (nerviosa, eléctrica, prepotente y beligerante) y de la mecánica vehicular y muscular 
(Hinz, p. 43; 47), el avión se perfila como máximo exponente y continúa la dicotomía del ascenso/descenso proveniente de poéticas anteriores. Lo nuevo es ahora la noción de catástrofe: esta se vuelve manejable -o "piloteable".

A dos años de la publicación del "Manifesto", Marinetti lanza Mafarka le futuriste (1910), ${ }^{2}$ texto que combina la fetichización del avión con el tópico de la Kopfgeburt. En medio de un escenario épico atiborrado de "efectos especiales" (FAZ, 2005) y tras, justamente, de un "parto intelectual", un útero maquinal pare un "insomne" engendro metálico que a continuación se estrenará en un "vuelo virgen" (fabuloso tecnotópico patriarcal). Este furor visceral por la aviación sigue viento en popa y a la vez se "transcribe" cuando Marinetti intenta destronar todo régimen representacional bajo el reclamo por las parole in libertà (Salaris, 2008, p. 302). El manifiesto técnico de 1912, Teoría e invenzione futurista, reclama que los verbos se articulen en un "infinito energético" y que se acabe con "el freno" que presentan ciertos signos de puntuación. Simultáneamente se diseña el sujeto futurista, una pieza estético-energética de utilidad "funcionaria". Tales visiones por supuesto que provocaron reparos; por ejemplo, se señaló que el avance de la humanidad no podría agotarse ni en la conquista de los cielos ni en la medida del espacio maquinal alado. Además, se criticaba que Marinetti invertía mucha energía 'revolucionaria' en ademanes escandalosos para aumentar su fama (por ejemplo, en el caso de L'aeroplane del Papa, de 1914, texto que imagina el secuestro del máximo representante de la iglesia católica).

De ninguna manera puede omitirse el impacto que tuvo Marinetti para la conceptualización de la italianità de Mussolini (Demetz, 2004, p. 125). La aviática ${ }^{3}$ detonaría en la Primera Guerra Mundial ${ }^{4}$ e Italia jugaría un rol singular en este campo de fusión estética, tecnológica y bélica. ${ }^{5}$ Valga mencionar aquí la competencia que tenía Marinetti en Gabriele D’Annunzio, autor menos referido por los estudios del futurismo, aunque más distinguido como artista. D’Annunzio, que superaba a Marinetti también en términos políticos porque ocupaba el puesto de regente de Fiume (Gumbrecht, 2001), ya a partir de 1910 en sus conferencias de aviática había proyectado grandes planes de vuelo (Demetz, 2004, p. 130) y de hecho en 1918 encabezaría el vuelo sobre Viena, de manera tal que mientras "Marinetti y los suyos" indiscutiblemente se ocupaban de monopolizar el futurismo con sus productos, D’Annunzio lo estaba viviendo (p. 26). ${ }^{6}$ La postura de D’Annunzio había sido influenciada por la decadencia finisecular hasta 1908, cuando el autor asistió a una demostración de vuelo. A partir de ahí el "bardo nacional" se propone ser piloto (p. 127). Da fe de esta suposición la novela fundacional Forse che si, forse che no (1910), en la que el protagonista es acompañado en su iniciación futurista, de manera asombrosa, por una co-protagonista no subyugada por los intereses del superuomo sino partícipe activa de la trama, de la misión y visión aviáticas. La fama de elitista entre decadente, conservador y nostálgico de D’Annunzio se basa en una serie de anécdotas, por ejemplo, la siguiente. Roma, primavera de 1909: en un evento comercial con Wilbur Wright, ${ }^{7}$ D’Annunzio se queja de la mezcolanza de italiano e inglés norteamericano que se hablaba en el aeródromo. Sobre esta queja, el amante de los antiguos diccionarios (re)introduce como alternativa a "aeroplane" la palabra "velivolo" (Farrell, 1993, p. 24). El término, aunque parecía caduco, se adaptaría a la nueva era (Demetz, 2004, p. 127). Otra: en septiembre del mismo año, buscando datos para futuras novelas aviáticas y aprovechando un espectáculo de vuelo quizás presenciado también por Kafka, ${ }^{8}$ D’Annunzio intenta convencer a Louis Blériot para que lo lleve consigo en un vuelo. Por más que recitara versos de su elegía icaria, no es escuchado; hasta que el fabricante y aviador Glenn Curtiss se lo lleva a modo de simulacro, y finalmente un joven italiano lo sube a una altura de 50 metros (pp. 127-132). Entretanto, Marinetti, en la guerra ítalo-turca (1911-1912), da prueba de la veracidad de su poética acudiendo a experiencias militares. Cuando Carlo Maria Piazza en noviembre de 1911 hace uso de su monoplano no para el sondeo sino para un bombardeo, Marinetti le responde con dos textos (p. 126).

D’Annunzio en cambio entra en función bélica recién en 1915, participando de vuelos arriesgados: al sobrevolar Trieste y otras ciudades adriáticas, y al girar sobre Viena, cae en el fuego de la defensa austríaca. Los textos que nacen a raíz de estas experiencias abandonan el estilo rimbombante. John Woodhouse (1999) indicaría el valor de estos billetes improvisados (Demetz, 2004, pp. 131-132). 
Para resumir: los italianos se pronunciaron por el "nacimiento de una nueva sensación", adecuada a una era más heroica que la Antigüedad. La aviática poética se adaptaría a este anhelado "fin de la prehistoria", y con la conquista bélica del siglo XX se volvería crudamente material (Benton, 1990, p. 28). El segundo futurismo conlleva nuevos manifiestos -en 1917 aparece La danza futurista que en "La danza dell' aviatrice" permite que una figura femenina, la danzatrice, juegue el papel del aviador (Veroli, 2000, p. 433)-. ${ }^{9}$ En 1919 sigue Il teatro aereo futurista de Fedele Azari. Ambos programas llevan la "tensión creadora y destructiva originalidad" hacia "nuevos rumbos restauradores”, pero fascistas (Peña Sánchez, 1998, p. 524). Remitiendo explícitamente a los campos de batalla (Veroli, 2000, p. 433), "La danza de la mitragliatrice" celebra un arma que había cobrado máxima importancia en la guerra moderna.

\section{EL FUTURISMO EN LA MIRA HISPANOAMERICANA: HÉLICES REALMENTE NUEVAS}

El entusiasmo por la agresión y la destrucción llevaría a que el futurismo italiano fuera criticado desde otro ismo, esta vez, hispanoamericano. Vicente Huidobro, antes de emprender la escritura de Altazor (Huidobro, 1931 [1919]), en "El futurismo" (Huidobro, 1914), dejaría claro que la supuesta innovación de Marinetti no era tan inédita: "se le ocurrió al señor de Marinetti proclamar una escuela nueva: El Futurismo. ¿Nueva? No" (Huidobro, 1914, p. 163). Efectivamente, el verso libre ya había sido introducido por Marie Krysinska o Gustave Kahn, y muchas de las ideas marinettianas se encontraban anticipadas en las letras hispánicas, por ejemplo por Gabriel Alomar olvaro Armando Vasseur. ${ }^{10}$ De este modo, Huidobro, además de despotricar sobre la ("infantil") misoginia de Marinetti (p. 167), subrayaría la existencia de otras poéticas futuristas, ambientadas en las Américas. Es Uruguay el primer país latinoamericano que publica el manifiesto marinettiano fundacional. También el peruano Juan Parra del Riego, residente en Montevideo, después de Vasseur, mantiene la línea futurista en el Cono Sur (Rocca, 2019, pp. 871-872). Fascinante es la escritura de Alfredo Ferreiro: El hombre que se comió un autobús (Poemas con olor a nafta) (1927) y Se ruega no dar la mano (poemas profilácticos a base de imágenes esmeriladas) (1930), dos verdaderas obras maquinistas.

En México, después de un artículo titulado "La paleta del futurismo" escrito por José Juan Tablada (1912), la Revista de Revistas comparte una reseña sobre la gran exposición futurista en el Palazzo Cova de Milano (primavera de 1919): “El futurismo: La última palabra en el arte”. En 1920, el muralista Carlos Mérida en El Universal Ilustrado se explaya a su vez sobre esta corriente de arte y en 1921 Revista de Revistas lanza la traducción de La danza futurista. En el mismo año, el también muralista David Alfaro Siqueiros redacta un manifiesto propio (" 3 llamamientos de orientación actual a los pintores y escultores de la nueva generación americana") que se publica en Barcelona y declara al arte latinoamericano como antídoto al "azucarado" art nouveau (Delgado Moya, 2019, p. 684). En la siguiente década, el mismo autor exhorta el amor por lo maquinario a través de distintas obras. Por su parte, el estridentismo, encabezado por Manuel Maples Arce, reacciona de manera más inmediata (Delgado Moya, 2019, p. 685 y ss.), y migra hacia los escritos de Marinetti (Gallo, 2012, p. 142). Al igual que el autor italiano, Maples Arce presenta un manifiesto fundacional: “Actual n 1 . Hoja de Vanguardia" (diciembre de 1921), ${ }^{11}$ que señala la expiración de otros ismos, incluido el creacionismo de Huidobro, y presenta un catálogo de "anticipaciones poemáticas novilatitudinales" referido a la lógica publicitaria, al mundo farmacológico y otros elementos citados con avidez. Infestado por la idea de la urbe y la virilidad fast-and-furious (Delgado Moya, 2019, p. 686), el estridentismo respira la pujante atmósfera de un México industrializado. Maples Arce reclama el volante para la travesía automovilizada de este paisaje, y se remite explícitamente a las “iluminaciones subversivas” de Marinetti (Maples Arce, 1921).

En 1924, el máximo estridentista le rinde homenaje a la ciudad revolucionaria y a los obreros mexicanos con "Urbe. Superpoema bolchevique en cinco cantos". En 1927, año que sellaría el gros de las actividades del movimiento, con Poemas interdictos, este autor ofrece algunas variaciones tipográficas, pero sin alcanzar las propuestas marinettianas. También, en términos más generales, los textos de Maples Arce, según Delgado 
Moya (2019, p. 690), albergan objetos modernos, pero mantienen rasgos de un lenguaje poético aprobado. En el contexto de este dosier, llama la atención el poema "Canción desde un aeroplano", en el cual la instancia poética, con la ayuda de "hélices nuevas", se alza hacia alturas eufóricas donde, entre "rosas aéreas" y otras "metáforas inefables", evoca lo inminente y el futuro mecanizado (Maples Arce, 1927, p. 117). Y aunque Maples Arce ya había refutado el creacionismo, "Canción desde un aeroplano" presenta analogías con respecto a Altazor: una versificación en parte escalonada y otros (si bien leves) desplazamientos, además de la postura de enunciación de la instancia vocal -el canto. Sin embargo, "Canción desde un aeroplano" respira un aire menos impuro, menos contaminado por otros ismos que Altazor (Ortega, 2000, p. 11). No sin razón, al sobrevolar ciudades y océanos, la instancia poética constata estar a la "intemperie / de todas las estéticas" y así proyecta el tópico de tabula rasa (o, para anticipar el concepto: de cielo abierto); una pantalla sin inscripciones, apta para recibir al futuro (Maples Arce, 1927, p. 117). ${ }^{12}$

Mucho más se podría decir sobre los futurismos entre Italia e Hispanoamérica y de la poesía motivada por el advenimiento de la aviación europea. Un último ejemplo: el poeta y columnista dominicano Virgil Díaz, al introducir, tras una estancia en Nueva York y París, el verso libre en su país con un poema titulado "Arabesco" (1917), crea un movimiento singular (y unipersonal) que nunca recibiría el merecido reconocimiento: el vedrinismo (Gutiérrez, 1998, pp. 5-15; Mora Serrano, 2011). ${ }^{13}$ El vedrinismo nace en homenaje a Jules Védrines, ágil aviador y ganador de la carrera aérea internacional París-Madrid en 1911 y del Trofeo Gordon Benett en 1912. Para su propuesta poética, Virgil Díaz reclamaba la misma agilidad que Védrines manifestaba en el cielo (en una ocasión este arrojó flores, en otra, octavillas sobre París, en el último caso pidió un aumento de aeronaves para el ejército francés). Piloto de un Blériot XXXVIbis bautizado $L a$ vache, Védrines despegó por última vez en un Caudron C 23 el 18 de mayo de 1919, antes de estrellarse cerca de Lyon.

La muerte de este piloto francés que inspiraría al poeta dominicano forma parte de una serie de muertes "heroicas" en el albor del siglo XX y otras acontecidas más tarde: la de Antoine de Saint-Exupéry, en 1944, y la de otros miembros de la Aéropostale que volaron entre Sudamérica y Francia. También la agonía del piloto franco-peruano Jorge Chávez, ocurrida tras un cruce de los Alpes en 1910, se vuelve legendaria por unas supuestas últimas palabras (Gagliardi Kindlimann, 2010) que además de crear relatos especulativos se convertirían en un modelo para los futuristas italianos (Benton, 1990, p. 25).

Valga también una muy puntual mirada sobre la poesía aviática en España. Tras un furor neo-romántico de la poesía escrita en catalán, Josep Maria Junoy se decide por una europeización poética y compone una serie de caligramas. "Deltoides (A Nijinski)" (1917) le rinde homenaje al legendario bailarín Vaslav Nijinski, célebre por sus saltos aparentemente ingrávidos. En la misma admiración por la elevación, le brinda un homenaje a Georges Guynemer, piloto de la armada francesa caído en $1917 .{ }^{14}$ Mientras que "Deltoides" recorre en tres "estrofas" una pirueta tautológica y evoca la musculatura (divina) de Nijinski, la "Oda" juega con las verticales y horizontales del vuelo y se inscribe en un cielo letrado. Elogiada por Apollinaire como "plastique poétique" (Mas López, 2004, p. 114), la "Oda” hace palpable la concepción del piloto como ser superior (literal y espiritual). ${ }^{15}$ Y justamente esta idea de la superioridad aviática se trasladaría también a la historia de la arquitectura, en una ramificación más del futurismo internacional.

\section{“LA LEÇON DE L'AVION" PARA CIUDADES EUROPEAS Y SUDAMERICANAS: NI PÁJAROS, NI MURCIÉLAGOS}

En 1923, en el texto-manifiesto Vers une architecture, ${ }^{16}$ Le Corbusier se expresa en favor de todas las actividades y expresiones industriales. Con este ademán, plasma entre las máquinas y los objetos productivos también a los espacios habitables, aunque denuncie su estado de arte: "La machine que nous habitons est un vieux coucou plein de tuberculose" (Le Corbusier, 1995, p. 233). El urbanista no es funcionalista en su decir, 
más bien se sirve de una imagen polivalente: coucou como el ave de fama ambigua -anunciador de la primavera pero también parasitario de nidos-; coucou como metonimia de un miembro de la familia de las máquinas medidoras de tiempo y de los pájaros cantores mecánicos; y, finalmente, coucou como designación de una avioneta destartalada. Después de la propaganda aviática del futurismo italiano, Le Corbusier prosigue con el paradigma del avión, pero lo hace para maldecir la arquitectura de su tiempo. Si Marinetti había hablado de una Italia caduca y reclamado su dinamización poetizando al automóvil y al avión, ${ }^{17}$ Le Corbusier acude al avión ya bautizado. ${ }^{18}$ Harto de las viviendas de su tiempo y de los interiores obsoletos, el urbanista se queja de que la arquitectura que lo rodea no se inquieta por el mañana. Y así, ocurre que el avión se le revela como un producto de "plus haute sélection", moldeado por la guerra, pero salido de una imaginación ideal: "On peut... affirmer que l'avion a mobilisé... l'imagination et la raison froide” (Le Corbusier, 1995, p. 85 [cursiva del autor]). ${ }^{19}$ En esta misma línea, la fórmula indispensable para un futuro logrado, según Le Corbusier, dicta: no soñar y no remitirse a nada dado, o, en términos mitológicos y genealógicos: no orientarse ni en el pájaro, ni en el murciélago. ${ }^{20}$ Le Corbusier prosigue: "Désirer voler comme un oiseau, c'était mal poser le problème, et le chauve-souris d'Ader n'as pas quitté le sol. Inventer une machine sans souvenirs” (p. 89). ${ }^{21}$ Así las cosas, la "propulsión" ideada por Le Corbusier se ve provista de alas, pero es fría: "L'homme intelligent, froid et calme, a acquis des ailes" (p. 100). El ciudadano frío y calmo representa el habitante sui generis de las nuevas ciudades.

La ciudad fue concebida como espacio futurista por excelencia. ${ }^{22}$ ¿Cómo se inmiscuiría en este espacio iluminado por la luz eléctrica, habitado por los vapores y cubierto de afiches de publicidad y todo un sinfín de estímulos contaminantes (o estridentistas), no solamente el paradigma sublime del vuelo, sino además muy concretamente el avión? En 1927, Fritz Lang proyecta un espacio monumental urbano fundado sobre distintas propuestas urbanísticas de su tiempo (Le Corbusier, otras anteriores, y la ciudad rascacielos de Ludwig Hilberseimer). Pero la imagen que Lang capta en Metropolis es la de una ciudad atrofiada y estratificada entre bonzos y obreros esclavizados, una maraña expresionista. Sin embargo, y a eso vamos, ni la ciudad futurista de Marinetti, ni la ciudad futurista funcionalista, tan explícitamente inspirada en la ingeniería aviática, integraban la realidad de la aviación directamente, mientras que la de Fritz Lang sí: los cielos de Metropolis, además de estar tapados por los rascacielos, se ven poblados por aviones.

¿Cuáles serían las razones para esta aparente paradoja? Estrenada por la Primera Guerra Mundial, la aviación no ocupaba aún un lugar comercial, ni estaba integrada en la circulación civil. Tras sus inicios inventivos se inscribía más bien en la experimentación determinada por un giro espacial, siendo catalizadora frente a un nuevo sistema relacional de variables muy inesperadas (Asendorf, 1997). Y así, aunque los cielos urbanos sí conocían las exhibiciones de vuelo, la aviación aterrizaría solamente más tarde en las ciudades, y con frecuencia en sus zonas periféricas.

En 1929 -el mismo año en el que Marinetti publica su Primodizionario aereo italiano- Le Corbusier viaja a Sudamérica invitado por Victoria Ocampo y Paulo Prado (Felipe Torres, 2015; Alonso García, 2016). Queda fascinado por los paisajes urbanos de Buenos Aires, Rio de Janeiro, São Paulo y Asunción, que tanto se diferenciaban de las ciudades europeas. Para este periplo, Le Corbusier realiza su trayecto más extenso en barco, pero ante todo vive su primer vuelo (Felipe Torres, 2015; Fraser, 2011, pp. 235-236). Esta experiencia resuena seis años más tarde en Aircraft (1935), ${ }^{23}$ donde se resalta la belleza y rigurosa funcionalidad del avión, y el correspondiente espectáculo de percepción: la vista, ahora sí, de pájaro, en la que aparentemente se condensa el mundo. El avión resulta ser un vehículo iluminador: "aerial vision permitted a rather different kind of gaze; this gaze was abstract and it was targeted" (Adey, 2010).

Sin duda, Le Corbusier proyectó sobre el territorio sudamericano una visión exotizante; a la vez, la "visión de América" del urbanista quizás haya sido influenciada desde la vanguardia brasileña antropofágica (Fraser, 2011, pp. 238-239). La gira sudamericana realizada por Le Corbusier ampliaría la visión proyectual y creativa de este. Pues la vista sobre el generoso paisaje fluvial de los ríos Paraná y Paraguay en el vuelo entre Buenos Aires y Asunción daría luz a la "loi de méandre" (Fraser, 2011, p. 236); aparentemente, la percepción 
microscópica desde el avión y las ciudades sudamericanas suscitaron una aprehensión más localizada y menos progresista en Le Corbusier, un interés por la materialidad y la topografía específicas y, finalmente, una visión poética (Pérez Oyarzún, 1991, p. 32). ${ }^{24}$

En este gran contexto de las sensibilidades por los espacios y especialmente por los espacios sobrevolados, hallamos al avión en medio de la urbanística sudamericana. Valga recordar que, en 1933, Le Corbusier lidera La charte d'Athènes (1944 [1933]), y define "la ville fonctionelle". ${ }^{25}$ Esta ciudad de zonificación estricta y enfática con las construcciones altas (o elevadas, 'despegadas'), se volvería realidad en unos de los países que el urbanista visitó en 1929. La capital artificiosa y periférica de Brasil, Brasilia, se inauguró en 1960 cumpliendo con muchas pautas de La charte. Pero, ante todo, Brasilia hace entrever una figura fundacional que, si bien pensada como cruz, en las tomas aéreas y con miras al plano piloto de la ciudad, se impone como la silueta de un avión (Wrobel, 2019, p. 302-304). De tal modo, la exaltación a la aviación de las primeras décadas del siglo XX, se continúa en los años sesenta, en una fase muy avanzada de la modernización, en Latinoamérica. Y si aún hoy miramos el Eixo Monumental de Brasilia, presenciamos un halo de estética aerodrómica.

\section{LOS AEROPUERTOS, ESPACIOS DESNUDOS: UNA ANACRONICIDAD INTERCONTINENTAL}

A primera vista, no hay mucho escrito sobre los aeropuertos desde las ciencias de la cultura y mucho menos desde los estudios literarios. Sin embargo, desde los campos de investigación y reflexión colindantes, Paul Virilio y Marc Augé sirven como referencias teóricas para abrir un sondeo. Si bien muy citados, valga recordar los non-lieux de Augé (1992), estos lugares no-antropológicos, sin historia pero significantes en lo relativo a la desmesura acontecimental y la saturación espacial de la sobremodernidad. Transitorios, hechos para el consumo y de pronta consumación, se presentan de manera encadenada o en forma carrefour. Pero un no-lugar cambia dependiendo de si se consume o, al contrario, se trabaja en él: un criterio para pensar los aeropuertos.

Más recientemente, Andrea Urlberger, tras una investigación interdisciplinaria e intervenciones in situ, publicó Habiter les aéroports: paradoxes d'une nouvelle urbanité (2012). Si bien en su subtítulo evidencia una paradoja, esta obra hace hincapié en la permeabilidad del aeropuerto: supeditado a la movilidad aérea (y la circulación de datos y combustibles), el aeropuerto es una zona libre y a la vez vigilada y, además, un espacio para el juego, la intimidad y la ficción.

Mientras las estimaciones de Urlberger se refieren al aeropuerto de nuestra hipermodernidad, los primeros aeropuertos civiles nos devuelven a los años 30 del siglo XX. Nueva York, que en aquel entonces albergaba el rascacielos más alto del mundo, en 1939 inauguró el aeropuerto LaGuardia. En muy poco tiempo este colapsó bajo el alza de la circulación aérea hacia The Big Apple. Sin embargo, el carácter de lo efímero pesa sobre todos los aeropuertos del mundo de la época (Streitz, 2007) y Alistain Gordon (2008 [2004]) inclusive compila vastas pruebas para un intrínseco anacronismo aeroportuario (años 40 a 70). Este fenómeno es asimismo comentado por la literatura: la novela Airport de Arthur Hayley (1968) ambienta su acción en un aeropuerto ficticio de Chicago que no da abasto con el arribo de los jumbos.

Esta inadecuación de los aeropuertos en Norteamérica se debía a que la vanguardia aviática se encontraba en Europa, donde los aeródromos de guerra se habían vuelto civiles. Así, y pese a que habían sido pensados como faros del progreso, los aeropuertos del Nuevo Mundo eran miserables, o se encontraban en manos privadas. Recién en los años 50 llegaría una época dorada con un diseño propio que superaría la lógica de otras terminales de transporte (ferroviarias), como es el caso de la arquitectura 'ascendiente', ligera y transparente de Eero Saarinen para el terminal TW A en el aeropuerto J. F. Kennedy (Streitz, 2007), ejemplo, entre otros, que Gordon aprehende de manera nostálgica para identificar los avatares de una escasa estética utópica "birdlike" aeroportuaria. ${ }^{26}$ En este lapso irrumpe el comienzo del terrorismo internacional que convierte a los aeropuertos en los frentes de una guerra de nuevo calibre. Así, Virilio (1984) observa que 
la transparencia y la joven personalidad aeroportuaria habrían sucumbido bajo los nuevos requerimientos de seguridad, reduciéndose a una función de infraestructura. En los últimos tiempos esto ha cambiado, ya que la liberalización y privatización no solamente del tráfico aéreo sino también de los aeropuertos (aproximadamente 10\% del total mundial) crea verdaderas plataformas comerciales (CEPAL 2015, pp. 3-4, 7). A la vez, la creciente demanda del transporte aéreo del próximo futuro (Juniac, 2018) prolongará el desajuste anacrónico de estos espacios logísticos y de su estética.

Volvamos a Le Corbusier. En "L'architecture et les aéroports modernes" (1946), señala que el aeropuerto debería ser un espacio desnudo: "Un aéroport semblerait donc devoir tre nu, entirement plein ciel, pleine prairie, pleine piste de ciment" (p. 191). Frente a tal "splendeur de l'espace", la arquitectura de las máquinas aladas superaría cualquier arquitectura de edificio. Es más: tras el no a la golondrina de los años veinte, Le Corbusier (p. 191) ahora alaba la armónica "biología" de los aviones. ${ }^{27}$

Mucho ha pasado desde entonces, pero la historia de la estética aeroportuaria aún debe ser descrita; sobre todo la del mundo hispánico. En este contexto, parecería oportuno subrayar que la cita de Le Corbusier expresa una predilección nacida aún en los aeródromos de los pioneros y aventureros. Efectivamente, el urbanista en 1929 coincide con nadie menos que Antoine de Saint-Exupéry (que, dicho sea de paso, fue estudiante de arte y arquitectura antes de volverse piloto), ${ }^{28}$ cuando este trabajaba en Buenos Aires para Aeroposta Argentina S.A. El autor francés que, como otros de sus compañeros de la Compagnie Générale Aéropostale sentía estar destinado a vivir "a cielo abierto" (Iturbe, 2018; Abós, 2018), invita a Le Corbusier a que suba a su avión. Probablemente las declaraciones del urbanista sobre los aeropuertos fueron inspiradas por tal ademán pionero, por esta pasión.

\section{Cielos ABIERTOS: ESPACIO CONQUISTADO POR EL AUTOR-AVIADOR, TÓPICO CONTAMINADO}

La noción de "cielo abierto" le da título a una novela del autor español Antonio Iturbe (2018), quien, justamente a través del lente de Saint-Exupéry, enfoca la época cosmopolita de la aviación iniciada en Toulouse-Montaudran por Pierre-Georges Latécoère. Encabezada por el mismo Saint-Exupéry, además de Jean Mermoz y Henry Guillaumet, Aéropostale, tras el primer tramo Francia-África, se vuelve transatlántica con las oficinas sudamericanas y en 1930 cruza el océano en su primer vuelo sin escalas. ${ }^{29} \mathrm{El}$ texto de Iturbe inicia con un típico establishing shot, una escena mecánica-acrobática. Un discurso inagural extradiegético tematiza "el milagro" de la elevación aviática: un "pesado armario rodante" "se torna ligero" y despega del suelo (Iturbe, 2018, p. 11). Aparece Saint-Exupéry, citando a Mallarmé (p. 13), padre de una poética fundamentada en el binomio de la elevación/ascensión, y del simbolismo estelar. Mallarmé es para Saint-Exupéry una estrella fija; al cabecear su Caudron C.59 sobre el aire, el futuro autor de El principito a su vez cabecea dándole razón a la concepción del silencio mallarmaniano. El silencio en el cielo se corresponde con un movimiento sublime, elevado, pero las piruetas que se necesitan para que esto se logre sitúan al aviador al borde del abismo (o "picado escalofriante") (p. 13). No obstante en la tierra, el aviador es controlado por los directores de la empresa aérea: burócratas y sumisos de diferentes intereses mundanos.

A cielo abierto pinta a Mermoz como el personaje (insaciable) que más aborrece la inmovilidad: ${ }^{30}$ "media docena de biplanos permanecen quietos sobre el asfalto del aeródromo. [Mermoz] [s]iente el rugir del estómago..., pero nota también otro vacío que le gruñe en las tripas: el de volar” (p. 32). Mermoz desprecia a la "gente sin vocación", los suboficiales que tras la fama de la guerra se hundieron en la "normalidad aséptica de la paz" (p. 32 y ss.). En esta percepción, la vida terrícola es equivalente a cierta estrechez de mente, y los espacios bajos y cerrados, a saber, los cuarteles, cortan la respiración. Solamente en el cielo Mermoz se serena, es decir, ahí donde "hay que hablar poco y escuchar mucho" (p. 45). La sonoridad sublime de la máquina voladora, no obstante, en cualquier momento puede caer en el silencio de algún siniestro: "todo se funde de negro y se hace el silencio" (p. 49). 
En A cielo abierto, dos siniestros que marcaron la historia de Aéropostale hacen palpable cuán expertos eran los pioneros de la aviación en milagros (p. 271): Henry Guillaumet sobrevive en los Andes en 1930; Mermoz en 1929, tras errar por una zona que no devuelve a la gente (p. 360). Pero el cielo abierto llama de nuevo. ${ }^{31}$ No sin razón, este tópico aparece en escritos del propio Saint-Exupéry y, más tarde, en una novela como La promesse de l'aube de Romain Gary. Aquí, una madre hiperambiciosa obliga al narrador autodiegético al ascenso máximo: “-Guynemer! Tu seras un second Guynemer! Tu verras, ta mère a toujours raison!... -Tu seras un héros, tu seras général, Gabriele D’Annunzio...!” (Gary, 1980, p. 16).

Los "delirios" que estas dos novelas, una francesa, una española, literaturizan, habrán sido motivados por algunos de los aspectos histórico-culturales expuestos hasta aquí: el deseo dialéctico por el movimiento y la quietud, el estruendo y el silencio, así como la vista privilegiada del viaje aéreo, la metamorfosis de las superficies que se presencia a través de él: "Desde el aire el mar es otra cosa" (Iturbe, 2018, p. 321). Pero ya dos décadas más tarde, siendo los vuelos más comunes, Adorno (1954) tilda esta perspectiva de institucionalizada y aplomada.

En el topos del cielo abierto se dan cruces entre la poética y la política, la ética y la estética. Más allá de esto, el tópico se traduce en distintos instrumentos, como el Open Sky Agreement (Tratado de Cielos Abiertos), un programa militar de vigilancia aérea multilateral firmado en los años noventa entre más de 30 naciones, o el Acuerdo de Cielos Abiertos civil entre Estados Unidos y la Unión Europea de 2007, que facilita la operación de rutas aéreas en territorios extra-nacionales. A la vez, le da título a la traducción inglesa de una obra de Virilio, La vitesse de la Libération (1995), que entiende al cielo como la versión óptica de la atmósfera, como el gran lente del globo terráqueo, como su brillante retina (Virilio, 1997, p. 1). Muy viriliano, este texto alude a la velocidad desaparecedora, para decantarse después sobre la palabra "skyline" (a saber, el límite vertical que separa "lo vacío" de "lo lleno"), representativa para toda una semántica del cielo. Pero Virilio habla también del perspectivismo renacentista y sus graduaciones epistémicas, hasta referirse a nuestra manera actual de mirar el cielo, tan afectada por el desorden ecológico. La época de la contaminación, según la lección de esta obra del pensador francés, pide revisar nuestra "perception of appearences", como también los límites geopolíticos y los de la geometría que se vuelcan sobre el paisaje tan transparente de nuestro mundo (Virilio, 1997, pp. 1,3). Una perspectiva parecida a la del dromólogo, pero más reciente, ofrece Aerial Life: Spaces, Mobilities, Affects, de Peter Adey (2010).

\section{A MODO DE RESUMEN: “¿DóNDE... HACE NIDO EL AVIÓN?”}

A partir de la segunda década del siglo XX, en la construcción de textos y ciudades y, también, del cielo, aparece el avión como catalizador, arrastrando visiones románticas e inagurando perspectivas microscópicas y a la vez altivas, conquistadoras. Fraser (2011, p. 136) explica que el ojo, desde la inteligencia tecnológica y la perspectiva del avión, dejó de estar nublado ("clouded") por la subjetividad; y efectivamente; "the eye of a bird transplanted into the head of a man" nos remite al perfeccionamiento maquinal marinettiano. De tal modo, desde la época moderna hasta las vanguardias históricas y la hipermodernidad, hallamos un interés por la dinámica relacional y espacial entre los dispositivos vehiculares y los cuerpos humanos y "superhumanos", y trazando este recorrido llegamos a la figura del avión. Una última alusión a un capítulo del futurismo ayudará a ilustrar esta secuencia de ideas. La "aeropittura" intentó condensar las experiencias superiores del aviador cuando condujo la física de la versificación futurista (Demetz, 2004, p. 125) 32 y la física del superpoder fascista a otro álgido momento, pintando la tierra desde arriba y posicionando al hombre soberbio por encima de paisajes, militares y civiles, o inhóspitos y desolados. Hoy podríamos decir que esta vertiente de la historia del arte vanguardista optó por una top-down perspective, o un bird's eye-, helicopter-o overhead-view (como se dice en el cine). Una obra como Prima che si apra il paracadute, de Tullio Crali (1939), es ejemplar para esta estética cuya programática apostó por una "nuova spiritualità 
extraterrestre", explicando que "Le prospettive mutevoli del volo costituiscono una realtà assolutmante nuova” ${ }^{33}$ De cierta forma, la aeropintura puede ser asociada con el aerial landscape art, nacido a su vez en la segunda mitad del siglo XX. Mencionemos por ejemplo “Aerial Series" de Jane Frank, y especialmente la pieza "Sambura" (1970), una vista sobre el abstraído lustre diamantino de una ciudad nocturna. ${ }^{34}$ Sumamente actual en cambio, es decir de nuestro siglo, o, por decirlo así, antropocénico, es el geospatial art de Nikolas Schiller, que además de trabajar con Google Streetview, ${ }^{35}$ crea mapas imaginarios y fotografías aéreas caleidoscópicas que, ${ }^{36}$ muy a diferencia de la aeropittura histórica, son pacifistas y ecologistas.

Mucho más se podría indagar en las estéticas no solamente aviáticas, sino además del cielo (que siempre serán relevantes para la aviación). ¡Valga mencionar el cloud scape art (y sus antecedentes), que realza la plasticidad de un fenómeno observado por una muy pintoresca institución, la Cloud Appreciation Society! Asimismo, existen estudios sobre la codificación epistemológica de las nubes y su transposición a los textos literarios, la filosofía de la imaginación y la teoría de la fractalidad (Weber, 2012). Para cerrar este texto, proponemos contentarnos con la trayectoria ondulante y aladina de la nube cristal en el VI. Canto de Altazor (Huidobro, 1931, pp. 102-103) y dejar el espacio abierto para otro ensayo que se dedique a las estéticas recién mencionadas, y a otras más, por ejemplo las obras aerocénicas de Tomás Saraceno. ${ }^{37}$ Sin embargo, una última escala: desvelemos que Alfredo Ferreiro, en Se ruega no dar la mano -título tan higiénico-comparte todo una serie de amorosos poemas "aviónicos" (Ferreiro, 1930, p. 8, v. 3-9; p. 9, v. 1-4) que conjugan el deseo por la intimidad con la sensación del cansancio (metonimia del aterrizaje) y los conceptos del hombre motorizado, el "Aviador". Este "Prototipo del hombre" es designado como un "Moledor del sol" y "azotador de nubes" (p. 8, vv. 8-9) que "Enfilado y tranquilo / chisporroteando motor, / escribiendo audacia / con la tinta del humo / iba en procura / de una rotura / en la envoltura / del 'Zeppelin' del cielO” (p. 9, v. 1 [negrita en el original]). En este último poema, Ferreiro pinta un "Aviador de todos los tiempos" que escribe “con la tinta del humo". Recordemos las escrituras de humo de Raúl Zurita (2019), ${ }^{38}$ y, simultáneamente, la reescritura de esta poética en Estrella distante de Roberto Bolaño, y señalemos, antes de bajar los flaps alares, que Ferreiro igualmente parecería dialogar con Le Corbusier (y Huidobro): “¿Dónde, en qué nido de qué árbol / hace nido el avión?” (Ferreiro, 1930, p. 8, v. 4).

\section{REFERENCIAS}

Abós, A. (2018). Mira la catedral que habitas: La vida de Saint-Exupéry en la Argentina. Buenos Aires: Sudamericana. Adey, P. (2010). Aerial life: spaces, mobilities, affects. Oxford: Blackwell.

Adorno, T. W. (9 de enero de 1954). So ergeht es dem, der heute zum ersten Male fliegt. Frankfurter Rundschau.

Alonso García, E. (2016). Le Corbusier versus Fritz Lang. Imágenes contrapuestas de la ciudad en los años veinte. Cine y Arquitectura, 6, 12-13.

Asendorf, C. (1997). Super Constellation - Flugzeug und Raumrevolution. Viena y New York: Springer.

Augé, M. (1992). Non-Lieux. Introduction à une anthropologie de la surmodernité. Paris: Le Seuil.

Benton, T. (1990). Dreams of Machines: Futurism and l'Esprit Nouveau. Journal of Design History, 1(3), 19-34.

Berghaus, G. (2000). Futurism, Dada, and Surrealism: Some Cross-Fertilizations. Among the Historical Avant-Garde. En G. Berghaus (Ed.), International Futurism in Arts and Literature (pp. 271-304). Berlin: De Gruyter.

Bolaño, R. (1996). Estrella distante. Barcelona: Anagrama.

Bonillo, J. L. (2006). La modernité en héritage. Le CIAM9 d'Aix-en-Provence et la crise générationelle du Mouvemente Moderne. Rives Meditérranéennes, 24, 89-99. https://doi.org/10.4000/rives.561

CEPAL. (2015). Transporte y política aérea en América Latina y el Caribe en el contexto del desarrollo sostenible. Boletin FAL, 5(341), 1-8.

De Juniac, A. (2018). Die Luftfahrt wächst schneller als die Infrastruktur. Aero.de.Luftfahrtnachrichten. Recuperado de https://www.aero.de/news-28571/Die-Luftfahrt-waechst-schneller-als-die-Infrastruktur.html 
Delgado Moya, S. (2019). Early responses to The Foundation and Manifesto of Futurism. En Berghaus, G. (Comp.). Handbook of International Futurism (pp. 684-697). Berlín y Boston: De Gruyter.

Demetz, P. (2002). Die Flugschau von Brescia. Kafka, d'Annunzio und die Männer, die vom Himmel fielen. Viena: Zsolnay.

Demetz, P. (2004). Über Aviatisches - d'Annunzio, Marinetti, die Avantgarden und der Faschismus. En C. Klinger y W. Müller-Funk (Coords.), Das Jabrhundert der Avantgarden (pp. 123-132). München: Wilhelm Fink.

Farrell, J. (1993). The Age of Icarus-the Adventure of Flight in Gabriele d'Annunzio and Lauro de Bosis. En Hanner, M. (Ed.), Literature and Travel (p. 123-136). Amsterdam y Atlanta: Rodopi.

Felipe Torres, C. (2015). Latin America in the antipodes. Le Corbusier between airplanes and mulatas. Universidad de La Habana, 280, 140-152.

Frampton, K. (2002). Le Corbusier. Madrid: Akal.

Frankfurter Allgemeine Zeitung (FAZ) (2005; archivo actualizado). Mein Sohn das Flugzeug. Recuperado de https:/ /www.faz.net/aktuell/feuilleton/buecher/rezensionen/belletristik/mein-sohn-das-flugzeug-1235545.html

Fraser, V. (2011). Le Corbusier cannibalisé. Les Jardins du MES. En L. Cavalcanti y F. El-Dahdah (Coords.). Roberto Burle Marx: la modernité du paysage (pp. 231-239). Barcelona: Actar Editorial.

Gallo, R. (2012). 'Wireless Modernity': Mexican Estridentistas, Italian and Russian Futurism. International Yearbook of Futurism Studies, 2, 141-170.

Gagliardi Kindlimann, O. G. (2010). Jorge Chávez Dartnell. Centenario de la hazaña del cruce de los Alpes (1910-2010). Lima: Universidad Alas Peruanas.

Gary, R. (1980 [1960]). La promesse de l'aube. Paris: Gallimard.

Gordon, A. (2008). Naked Airport: A Cultural History of the World's Most Revolutionary Structure. Chicago: University of Chicago Press.

Gumbrecht, H.U. (2001). Der Dichter als Kommandant. D'Annunzio erobert Fuime. München: Fink.

Gutiérrez, F. (1998 [1995]). Antología histórica de la poesía dominicana del siglo XX, 1912-1995. San Juan de Puerto Rico: Editorial Universidad de Puerto Rico.

Hailey, A. (1968). Airport. New York: Doubleday.

Hinz, M. (1985). Die Zukunft der Katastrophe: mythische und rationalistische Geschichtstheorie des italienischen Futurismus. Berlín y New York: De Gruyter.

Huidobro, V. (1931 [1919]). Altazor o el Viaje en Paracaidas. Poema en VII cantos. Madrid: Compañía Ibero Americana de Publicaciones.

Huidobro, V. (1914). Pasando y pasando. Santiago: Imprenta y Encuadernación Chile.

Ingold, F. P. (1980 [1978]). Literatur und Aviatik. Europäische Flugdichtung 1909 bis 1927. Frankfurt a. M.: Suhrkamp.

Iturbe, A. (2018 [2017]). A cielo abierto. Barcelona: Seix Barral.

Kister, K. (2018). Erster Weltkrieg: Wie der Krieg das Fliegen lernte. Süddeutsche Zeitung. Recuperado de https://w ww.sueddeutsche.de/politik/erster-weltkrieg-wie-der-krieg-das-fliegen-lernte-1.3810981

Kohle, H. (2006). Stadtwahrnehmung in der futuristischen Malerei und im deutschen Expressionismus". En F. Lenger y K. Tenfeld (Coords.). Die Europäische Stadt im 20. Jahrhundert: Wahrnehmung - Entwicklung - Erosion (pp. 265-280). Köln, Weimar y Viena: Böhlau.

La charte d'Athènes (1944). Technique et Architecture, 7, 21.

Le Corbusier (1995 [1923]). Vers une architecture. Paris: Flammarion.

Le Corbusier (1935). Aircraft. London: Studio.

Le Corbusier (1946). L'Architecture et les aéroports modernes. En CEuvre complète: 1938-1946 (pp. 190-191).Zürich: Willy Boesiger.

Maples Arce, M. (1921). Actual n ${ }^{\circ}$. Hoja de Vanguardia. Enciclopedia de la literatura en México. Recuperado de htt $\mathrm{p}: / /$ www.elem.mx/institucion/datos/3585 
Maples Arce, M.(1927). Poemas interdictos. México: Ediciones de Horizonte.

Mas López, J. (2004). Josep Maria Junoy i Joan Salvat-Papasseit: dues aproximacions a l'haiku. Barcelona: Publicacions de l'Abadia de Montserrat.

Mora Serrano, M. (2011). Postumismo y vedrinismo: primeras vanguardias dominicanas. Santo Domingo: Editora Nacional.

Morales Fredes, C. (2017). Crónicas de aeropuerto. Santiago de Chile: Mago Editores.

Ortega, N. A. (2000). Vicente Huidobro - Altazor y las Vanguardias. México: Universidad Nacional Autónoma de México.

Pascoe, D. (2001). Airspaces. London: Reaktion.

Peña Sánchez, V. (1998). Sobre teoría y práctica teatral: la escena futurista. En J. Espinosa Carbonell (Comp.), El teatro italiano: Actas del VII Congreso Nacional de Italianistas (pp. 517- 526). Valencia: Universidad de Valencia.

Pérez Oyarzún, F. (Coord.) (1991). Le Corbusier y Sudamérica. Viajes y proyectos. Santiago de Chile: Escuela de Arquitectura, Pontificia Universidad Católica de Chile.

Rocca, P. (2019). Uruguay. En G. Berghaus (Ed.), Handbook of International Futurism (pp. 871-882). Berlin y Boston: De Gruyter.

Salaris, C. (2008). Die Futuristen und die Religion der Maschine. En H. Schramm, L. Schwarte y J. Lazardzig (Coords.), Spuren der Avantgarde: Theatrum machinarum. Frühe Neuzeit und Moderne im Kulturvergleich (pp. 298-312). Berlin y New York: De Gruyter.

Streitz, M. (2005). Von Lindbergh bis Bin Laden. Der Spiegel. Recuperado de https://www.spiegel.de/consent-a-?targetUrl=https\%3A\%2F\%2Fwww.spiegel.de\%2Fpolitik\%2Fdeutschla nd\%2Fs-p-o-n-im-zweifel-links-bin-laden-der-sieger-a-760646.html\&ref=https\%3A\%2F\%2Fwww.google.co $\mathrm{m} \% 2 \mathrm{~F}$

Urlberger, A. (Ed.). (2012). Habiter les aéroports: paradoxes d'une nouvelle urbanité. Ginebra: MétisPresse.

Van den Berg, H. (2014). Die Avantgardetradition dem Komformismus abgewinnen, der sie längst überwältigt hat? Einige Anmerkungen zum Avantgardebegriff im frühen 21. Jahrhundert. En Asholt, W. (Comp.), Avantgarde und Modernismus: Dezentrierung, Subversion und Transformation im literarisch-künstlerischen Feld (pp. 295-326). Berlin y Boston: De Gruyter.

Veroli, P. (2000). The Futurist Aesthetics and Dance. En G. Berghaus (Ed.), International Futurism in Arts and Literature (pp. 422-448). Berlin: De Gruyter.

Virilio, P. (1984). La ville surexposée . En L'espace critique. Paris: Éditions Christian Bourgeois.

Virilio, P. (1995). La vitesse de la Libération. Paris: Édition Galilée.

Virilio, P. (1997). Open Sky. New York: Verso.

Weber, A. (2012). Wolkenkodierungen bei Hugo, Baudelaire und Maupassant im Spiegel des sich wandelnden Wissenshorizontes von der Aufklärung zur Chaostheorie. Berlin: Frank und Timme.

Woodhouse, J. (1999): Gabriele d'Annunzio: defiant archangel. Oxford: Clarendon Press.

Wrobel, J. (2019). Benses Brasilien: Reflexionen zur konkreten Poesie, Brasília und dem Entwurf einer Rheinlandschaft. En Albrecht, A., et al. (Eds.), Max Bense: Werk - Kontext-Wirkung (pp. 291- 321).Stuttgart: Metzler.

Zurita, R. (2019 [1982]). La vida nueva. Versión final. Barcelona: Lumen.

\section{Notas}

1 Este ensayo no pretende de ninguna manera cubrir las pautas y los hitos de la historia tecnológica de la aviación, pero no se priva de aportar ciertos datos que ayuden a completar el cuadro de información impartido desde las ciencias culturales y literarias. Para algunos aspectos de la historia de la aviación veáse el ensayo de Guillermo Giucci en este dosier.

2 La traducción al español de esta obra data de 1921 y estuvo a cargo de Julio Gómez de la Serna.

3 Sobre este término, consultar la introducción y el texto de Felix Philipp Ingold en este dosier. 
4 Kurt Kister (2018) demuestra que durante la Primera Guerra Mundial la aviación expande los campos de batalla. Todas las grandes potencias involucradas hacen uso de aviones, de "caballeros del aire", globos aerostáticos y palomas mensajeras. En este contexto, son relevadoras las fotografías históricas del archivo de Süddeutsche Zeitung, imágenes romantizadas de "Militärtauben" (palomas militares), la fotografía de un avión alemán sobrevolando las pirámides de la meseta de Guiza, etc.: https://www.sueddeutsche.de/politik/militaergeschichte-erster-weltkrieg-als-feuer-vom-him mel-fiel-1.3811406-3

5 A diferencia de otras vanguardias europeas, la vanguardia italiana se vinculó a la derecha política. Bajo Giovanni Giolitti, Italia sufría un retraso (arretratezza) que no permitía su participación en el concierto de las otras naciones. Así, tras el cambio de siglo empieza a brotar un nacionalismo frustrado por la pérdida del aliento que había caracterizado al Risorgimento. Esta nueva consciencia, adversa a Giolitti, reclama una prontísima industrialización de Italia. Demetz (2004, pp. 23-25) afirma que sería menos dificil identificar la posición de Marinetti por entre las fuerzas políticas opuestas a Giolitti que explicar la fama que Marinetti adquiriría como poeta.

6 Ironía: al entrar Italia en la guerra, Marinetti, aficionado a los vehículos motorizados y con todo el élan conceptual por una motorización que terminara con el retraso italiano, es designado para trabajar en una sección de producción ciclista, mientras que D’Annunzio sobrevuela Viena (Demetz, 2004, p. 127).

7 Wright fue un empresario estadounidense que en 1900, con su hermano Orville y aconsejado por Octave Chute y los conocimientos de Otto Lilienthal, empezó a fabricar planeadores.

8 En septiembre de 1909, Kafka publica „Die Aeroplane in Brescia” para proyectar en la figura del aviador una temática recurrente, a saber, la distante soledad del artista. Probablemente se trate del primer texto aviático escrito en alemán. Sobre este texto de Kafka, consultar también el ensayo de Ingold en este dosier, además de Demetz (2002).

9 La danza futurista proponía desembarazar el cuerpo de todo tipo de musicalidad, para arrojarlo al ruido y las onomatopeyas. Fue Giannina Censi quien se prestó a la "danza aérea” como médium, imitando el vuelo de un avión. Vestida de manera ligera, aerodinámica (malla y gorro), parecía apta para asaltar los cielos y sobrellevar los esfuerzos del despegue. Este protagonismo femenino sin embargo se debía a la convicción esquemática de que la danza era para mujeres (Veroli, 2000, pp. 425, 433).

10 El mallorquí Gabriel Alomar (1873-1941) estuvo notablemente influenciado por el modernismo catalán y el novecentismo, además de D'Annunzio. El uruguayo Alvaro Armando Vasseur (1878-1969) formó parte de quienes introdujeron el simbolismo en Latinoamérica. En Cantos augurales (1904) y Cantos del nuevo mundo (1907) de Vasseur, aparecen categorías futuristas como la previsión, el presentimiento, la precreencia.

11 Ver la Enciclopedia de la literatura en México: http://www.elem.mx/institucion/datos/3585. El manifiesto arranca así: "En nombre de la vanguardia actualista de México, sinceramente horrorizada de todas las placas notariales y rótulos consagrados... con veinte siglos de éxito efusivo en farmacias y droguerías subvencionales por la ley, me centralizo en el vértice eclactante de mi insustituible categoría presentista, equiláteramente convencida y eminentemente revolucionaria, mientras que todo el mundo que está fuera del eje se contempla esféricamente atónito con las manos torcidas” (Maples Arce, 1921).

12 Más de seis décadas después de su proclamación, el estridentismo se volverá objeto ejemplar de un sondeo irónico en Los detectives salvajes de Roberto Bolaño (1998). Arturo Belano desea averiguar todo acerca de Maples Arce, figura de una vanguardia desubicada, que la novela sitúa entre las múltiples grafías poéticas del desplazamiento.

13 Gutiérrez (1998) sin embargo afirma que Virgil Díaz no habría realmente creado un movimiento poético dominicano y que la modernización de la poesía dominicana ocurrió con el postumismo (pp. 9-10). También indica que entre las obras panorámicas sobre las vanguardias hispanoamericanas de Verani (1986) y Schwartz (1991), únicamente la segunda menciona al vedrinismo.

14 Se pueden ver numerosas entradas fotográficas y constancias de actos conmemorativos dedicadas a Guynemer en el siguiente sitio: https://www.traditions-air.fr/texte/Guynemer_Georges.htm

15 Sobre este punto véase también el artículo de Wolfram Nitsch en este mismo dosier.

16 Para comprobar el estatus de manifiesto de este texto, véase la p. 96 del "Manuel de l'Habitation", que es casi una diatriba.Vers une architecture reúne ensayos que anteriormente fueron publicados en la revista L'Esprit Nouveau ( $\mathrm{n}^{\circ}$ 1-3, 5, 8-10 y 13-16). Al texto le ha sido atribuido una "perdurable importancia” también en términos literarios (Frampton, 2002, p. 22, 24). Nota bene: no se recuerda con la debida atención la participación del cubista Amédée Ozenfant.

17 Ver "À l'Automobile” (también conocido como “À mon Pégase”), publicado en 1905 en París, que fue recitado ya en 1903 en presencia de Alfred Jarry (Berghaus, 2000, p. 273). También D’Annunzio era amante de los automóviles; se movía en un vehículo llamado Per non dormire (Demetz, 2004, p. 127). La industria automotriz y la aeronáutica estaban muy emparentadas. La marca Avions Voisin arrancó con la fabricación de aviones en 1919, pero aún antes, coincidiendo con el nacimiento del futurismo, la industria automotriz invertía en las formas aerodinámicas: "Car manufacturers were building the image of speed" (Benton, 1990, pp. 22-23). 
18 Le Corbusier también era fanático de los automóviles. Tenía un Voisin (modelo 1928) llamado La Lumineuse que adoraba como un cuerpo vitruviano. Benton (1990, p. 31) comenta: "The legacy of Futurism sealed a romantic attitude towards cars and aeroplanes into the Modern Movement whose repercussions are still being felt today".

19 El capítulo de Vers une architecture titulado "Des yeux qui ne voient pas... Les avions" se ve ilustrado con 17 ilustraciones en total; 16 de ellas fotográficas, 15 de ellas representaciones de aviones. Una fotografía tomada desde el avión muestra un impresionante paisaje de nubes (p. 95), pero no consta de leyenda. Las imágenes se insertan en el texto de manera bastante disociada. Walter Gropius en Die Entwicklung moderner Industriebaukunst (1913) y Der stilbildende Wert industrieller Bauformen (1916) se adelanta a esta iconografía usada por Le Corbusier (Frampton, 2002, p. 24).

20 Le Corbusier trae además a colación la libélula: “la leçon de l'avion n’est pas dans les formes créées, tout d'abord, il faut apprendre à ne pas voir dans un avion un oiseau ou une libellule, mais une machine à voler" (1995, p. 85).

21 Clément Ader, polifacético ingeniero francés, construyó su primera máquina voladora de motor a vapor, Éole, en 1886, inspirado en la figura de un murciélago. El intento de vuelo fue frustrado. Prosiguió su trabajo con dos modelos más. Además, se pronunció y publicó sobre la aviación militar, ya en la primera década del siglo XX. Ader, al igual que Karl Jotho y Richard Pearse, se adelantaría a los hermanos Wright en la concepción de aeronaves de motores de combustión interna.

22 Marinetti expresaba un fuerte rechazo contra ciudades como Venecia. Sin embargo, y aunque Milano se encontraba en pleno proceso de industrialización y estaba bien interconectada con otras ciudades europeas, el futurista anhelaba justo un re-nacimiento de Venecia: militarizada e industrial, se podría convertir en un bastión moderno adriático, reflejo de la antigua Venecia imperial (y anticipación del imperialismo fascista) (Kohle, 2006, p. 267).

23 La obra contiene más de cien fotografías. Véase la obra original en inglés y su reedición (Éditions Parenthèses, 2017): http://fondationlecorbusier.fr/corbuweb/morpheus.aspx ?sysId=13\&IrisObjectId=6446\&sysLanguage $=\mathrm{fr}-\mathrm{fr}$ \&itemPos $=1$ \&itemCount $=2 \&$ sysParentId $=11$ \&sysParentName $=$ Home

24 Véase nuevamente también el artículo de Wolfram Nitsch.

25 La carta se lanza con motivo del IV Congreso Internacional de Arquitectura Moderna, que, cancelado en Moscú, se trasborda al Patris II y zarpa desde Marseille hacia Atenas (Bonillo, 2006). Se encuentra una grabación de este fascinante viaje en Youtube.

26 Gordon también expone una historia gráfica de los aeropuertos, incluyendo algunas proyecciones de ciudades aeroportuarias nunca realizadas; al final roza el incidente de nine eleven ("From Lindbergh to Bin Laden").

$27 \mathrm{Al}$ respecto, ver también Pascoe (2001, p. 288).

28 Iniciado como piloto de guerra en 1922, Saint-Exupéry en 1926 es contratado por Latécoère para manejar el corredor Toulouse-Dakar. En 1929 se traslada a América del Sur. Después de la exitosa publicación de Courrier sud (1929) y Vol de nuit (1931), en los años 30 se consagra al periodismo. Una estadía en 1936 en España motiva la escritura de Terre des hommes (1939). A un año de la publicación de Le petit prince (1943), Saint-Exupéry desaparece en un vuelo iniciado en Grenoble. Varias teorías sobre la causa de este accidente, más un indicio en 2003 en la costa de Marseille, aumentaron su fama póstuma ("mort pour la France”). Saint-Exupéry ya había sido homenajeado con el aeropuerto de Lyon Saint Exupéry (inaugurado en 1975).

29 La primera travesía del Atlántico sur (con escalas) es llevada a cabo por Gago Coutinho y Sacadura Cabral en 1922. A este cruce le siguen en 1926 el vuelo de Ramón Franco (hermano de Francisco Franco) y Julio Ruiz de Alda (Palos de la Frontera-Buenos Aires) y, por supuesto la travesía de Charles Lindbergh (Nueva York-París) en 1927. También deben ser recordados: el vuelo de Dieudonné Costes y Joseph Le Brix desde Senegal a Brasil en 1927, una serie de vuelos en el continente americano hacia al Polo Norte, sobre Tierra del Fuego (1928) y al Polo Sur (1929), más otros entre el hemisferio norte y sur (Buenos Aires-Nueva York, 1926). Siguen vuelos desde las Américas y Europa hacia el océano Pacífico, y Australia. Los años mencionados abarcan además numerosas fundaciones de aerolíneas nacionales (p. ej. Iberia y Lufthansa, 1927). En la tercera y cuarta década del siglo XX entran varias mujeres a la aviación: Amela Earhart (instruida por Neta Snook) en 1928 cruza el Atlántico; en 1937 desaparece junto a Fred Noonan, en un giro al mundo.

30 Mermoz desaparece ya en 1936 sobre el océano Atlántico, pero aun así es nombrado Caballero de la Legión de Honor en 1952. Hay suposiciones que vinculan el accidente mortal de 1936 con un sabotaje nazi operado desde Uruguay.

31 Además, se asoma el atractivo (¿erótico?) de los espacios intermedios, los "agujeros" del cielo: ante una de sus hazañas, Guillaumet pronuncia: "Me meteré por los agujeros” (Iturbe, 2018, p. 358). A la vez, cuando Saint-Exupéry es derribado y ‘bajado' por un caza alemán (1944), su percepción no solamente se vierte en un stream of consciousness orientado hacia lo terrestre, sino que además el autor-aviador vive un momento de cognición nostálgica en el que se percata de que no ha entendido, en la vida cómo funciona el amor (p. 617), que de joven le había parecido una energía capaz de "detener locomotoras" (p. 16).

32 Esta vertiente futurista, sin duda respaldada por la fotografía aérea de guerra, tras un manifiesto más de Marinetti, el Manifesto futurista dell'aeropittura dei bombardimenti (1942), cae en desgracia por beligerante.

33 Aquí se puede ver un detalle del cuadro en el archivo de la Salomon R. Guggenheim Foundation: http://www.exhibit ions.guggenheim.org/futurism/aeropittura/\#4 
34 Overwiew de las obras en cuestión: WikiArt. Visual Art Encyclopedia. https://www.wikiart.org/en/jane-frank 35 Sobre Nikolas Schiller y Streetviews: http://streetviewied.com/

36 Véanse los mapas aéreos del artista: http://lolmaps.com/

37 Ver la respectiva entrada en la página del artista argentino residente en Berlín: https://studiotomassaraceno.org/. 38 Ver nuevamente la introducción de este dosier. 